\title{
Wild Trypanosoma cruzi I genetic diversity in Brazil suggests admixture and disturbance in parasite populations from the Atlantic Forest region
}

\author{
Valdirene S Lima ${ }^{1}$, Ana M Jansen ${ }^{1}$, Louisa A Messenger ${ }^{2}$, Michael A Miles² and Martin S Llewellyn ${ }^{2,3^{*}}$
}

\begin{abstract}
Background: Trypanosoma cruzi (Kinetoplastida, Trypanosomatidae) infection is an ancient and widespread zoonosis distributed throughout the Americas. Ecologically, Brazil comprises several distinct biomes: Amazonia, Cerrado, Caatinga, Pantanal and the Atlantic Forest. Sylvatic T. cruzi transmission is known to occur throughout these biomes, with multiple hosts and vectors involved. Parasite species-level genetic diversity can be a useful marker for ecosystem health. Our aims were to: investigate sylvatic T. cruzi genetic diversity across different biomes, detect instances of genetic exchange, and explore the possible impact of ecological disturbance on parasite diversity at an intra-species level.

Methods: We characterised 107 isolates of T. cruzi I (Tcl; discrete typing unit, DTU I) from different major Brazilian biomes with twenty-seven nuclear microsatellite loci. A representative subset of biologically cloned isolates was further characterised using ten mitochondrial gene loci. We compared these data generated from Brazilian Tcl isolates from around America.
\end{abstract}

Results: Genetic diversity was remarkably high, including one divergent cluster that branched outside the known genetic diversity of Tcl in the Americas. We detected evidence for mitochondrial introgression and genetic exchange between the eastern Amazon and Caatinga. Finally, we found strong signatures of admixture among isolates from the Atlantic Forest region by comparison to parasites from other study sites.

Conclusions: Atlantic Forest sylvatic Tcl populations are highly fragmented and admixed by comparison to others around Brazil. We speculate on: the possible causes of Atlantic Forest admixture; the role of T. cruzi as a sentinel for ecosystem health, and the impact disrupted sylvatic transmission cycles might have on accurate source attribution in oral outbreaks.

\section{Background}

Trypanosoma cruzi (Kinetoplastida, Trypanosomatidae) infection is an ancient and widespread zoonosis distributed throughout the Americas south of 33' latitude, where it infects approximately 8 million people [1,2]. $T$. cruzi is eclectic in terms of its mammalian hosts and haematophagous triatomine vectors. Several hundred species of mammal and many of the 140 extant triatomine species maintain transmission of $T$. cruzi in wild

\footnotetext{
* Correspondence: martin.llewellyn@lshtm.ac.uk

${ }^{2}$ Faculty of Infectious and Tropical Diseases, London School of Hygiene and

Tropical Medicine, London, UK

${ }^{3}$ Molecular Ecology and Fisheries Genetics Laboratory, School of Biological

Sciences, Bangor University, Gwynedd LL57 2UW, UK

Full list of author information is available at the end of the article
}

(sylvatic) transmission cycles [2-4]. Transmission to the host occurs usually via contamination of the mucosae or abraded skin with infected vector faeces. Oral transmission to humans via contaminated foods, especially fruit juices and sugar cane, is increasingly reported, and suspected to occur widely among sylvatic mammals through opportunistic insectivory of triatomines [5].

T. cruzi population genetic diversity is well described at a species level. Six discrete typing units (DTUs) are now accepted by international consensus [6]. Dates for the origin of $T$. cruzi in the Americas range between 5 and 1 MYA (calibrated biogeographically at 100 MYA) [7-9]. Estimates for the MRCA of TcI strains, arguably the most widely dispersed and abundant of all the DTUs, are younger: 1.3-0.2 MYA [7]. Nonetheless, the 
age of TcI in the Americas has been sufficient to see this genotype expand throughout multiple ecological settings, from Amazonian forests [10] to highland Andean puna [11]. Furthermore, the last 1.3-0.2 MYA in Latin America have seen intense climatic fluctuations, including at least two glaciations [12]. The impact of Pleistocene cycles of warming and cooling on the biomic, ecological and species diversity of Latin America, in particular in Brazil and the Brazilian Amazon, are a matter of long debate [13]. Nonetheless, there is evidence that historical cycles of forest expansion, contraction and fragmentation have impacted on the current ecology of Brazil, including small mammal distribution and diversity [14].

Today the terrestrial ecology of Brazil is summarized by several distinct biomes or 'ecoregions' [15]. The largest of these is the Amazon basin to the north, bordered by the dryer Cerrado and seasonally flooded Pantanal to the south. North-eastern Brazil is dominated by the xeric scrubland of the Caatinga. Along the Atlantic coast of Brazil south of Recife, a tropical forest ecosystem, the Atlantic Forest, predominates. The diversity of wild TcI hosts across this ecological mosaic is striking: caviomorph rodents in the Caatinga [16]; lion tamarins in the Atlantic forest [17]; coatis, peccaries and felid carnivores in the Pantanal [18-20]; and multiple species of primates, marsupials and rodents in Amazonia [2]. Some important genera are widespread - especially Didelphid opossums. Human Chagas disease was once widespread in Brazil, especially in central and southern parts of the country [21]. Indeed, Chagas disease has probably been endemic in human populations in Brazil since the earliest human settlements more than 10,000 years ago. It is important not to overlook the impact that humans, an abundant and mobile T. cruzi host species, present throughout all Brazilian ecoregions, may have had on contemporary parasite diversity.

Parasite alpha diversity at a species level is recognised as a marker for ecosystem persistence, productivity, organization and resilience [22]. Put simply, those ecosystems in which host organisms are parasitized by an array of different parasite species, fairly evenly distributed among hosts and host species, are considered to be healthy. Furthermore, parasites, with their short lifecycles and rapid mutational turnover with respect to their hosts, can facilitate fine-scale analyses of host population dispersal and differentiation [23]. However, close association between host and parasite species is a prerequisite for the use of parasite genetic diversity to track host populations. Multi-host parasite lineages like TcI are therefore unsuitable for such applications. Nonetheless, there is some evidence that habitat fragmentation impacts on both $T$. cruzi diversity and prevalence of infection [24-26]. Thus, alpha diversity in a multi-host parasite like $T$. cruzi might be a useful proxy for parasite diversity as a whole, and thus for ecosystem health.

Multilocus microsatellite typing (MLMT) is now a widely established means of defining genetic diversity among TcI isolates and clones [27]. Simultaneous analysis of multilocus sequence data from the mitochondrial (maxicircle) genome (mMLST) provides a proven means of detecting genetic exchange among clones [25,28]. Here we undertook a comparison of representative TcI isolates from across the ecological diversity of Brazil, examining the relationship between biomes and diversity within biomes. We found considerable genetic diversity among several populations, and multiple instances of genetic admixture, especially in the Atlantic Forest region. We consider these data, and the potential affect of human-mediated habitat fragmentation on the diversity of wild TcI in Brazil.

\section{Methods}

\section{Parasite strains and biological cloning}

One hundred and seven strains, the great majority sampled from mammalian reservoir hosts captured at sylvatic foci throughout Brazil, were assembled for analysis and their genotype confirmed as TcI via sequencing of a short fragment of the glucose-6-phosphate isomerase (GPI) gene [29]. Details of strain origin are given in Additional file 1: Table S1 and geographic distribution in Figure 1. A total of fourteen strains were selected from across all biomes and biologically cloned using the plate cloning technique described by Yeo et al. [30].

\section{Microsatellite analysis}

Twenty-seven microsatellite loci, distributed across eight putative chromosomes, were amplified following previously described protocols across 107 strains [27]. A reduced subset of 19 microsatellites was employed to evaluate diversity among a larger panel of 161 samples including the original strains, derived clones and thirtythree previously published multilocus microsatellite profiles [28]. Population genetic diversity parameters were first calculated from sample groupings based on geography and biome for the full 27 locus dataset (Table 1). There were nine such groupings, as identified in Figure 1 and listed in Additional file 1: Table S1. Population-level genetic diversity was assessed first using sample size corrected allelic richness $\left(A_{r}\right)$ in FSTAT 2.9.3.2 [31]. Secondly, to provide a better measure on intra-population sub-clustering, mean pairwise $D_{\text {AS }}$ and associated standard deviation was also evaluated per population. $F_{\mathrm{IS}}$, a measure of the distribution of heterozygosity within and between individuals, was estimated per locus per population in FSTAT 2.9.3.2 [31]. Tests for population specific departures from Hardy Weinberg Equilibrium at specific loci were calculated in ARLEQUIN v3.1 and associated 


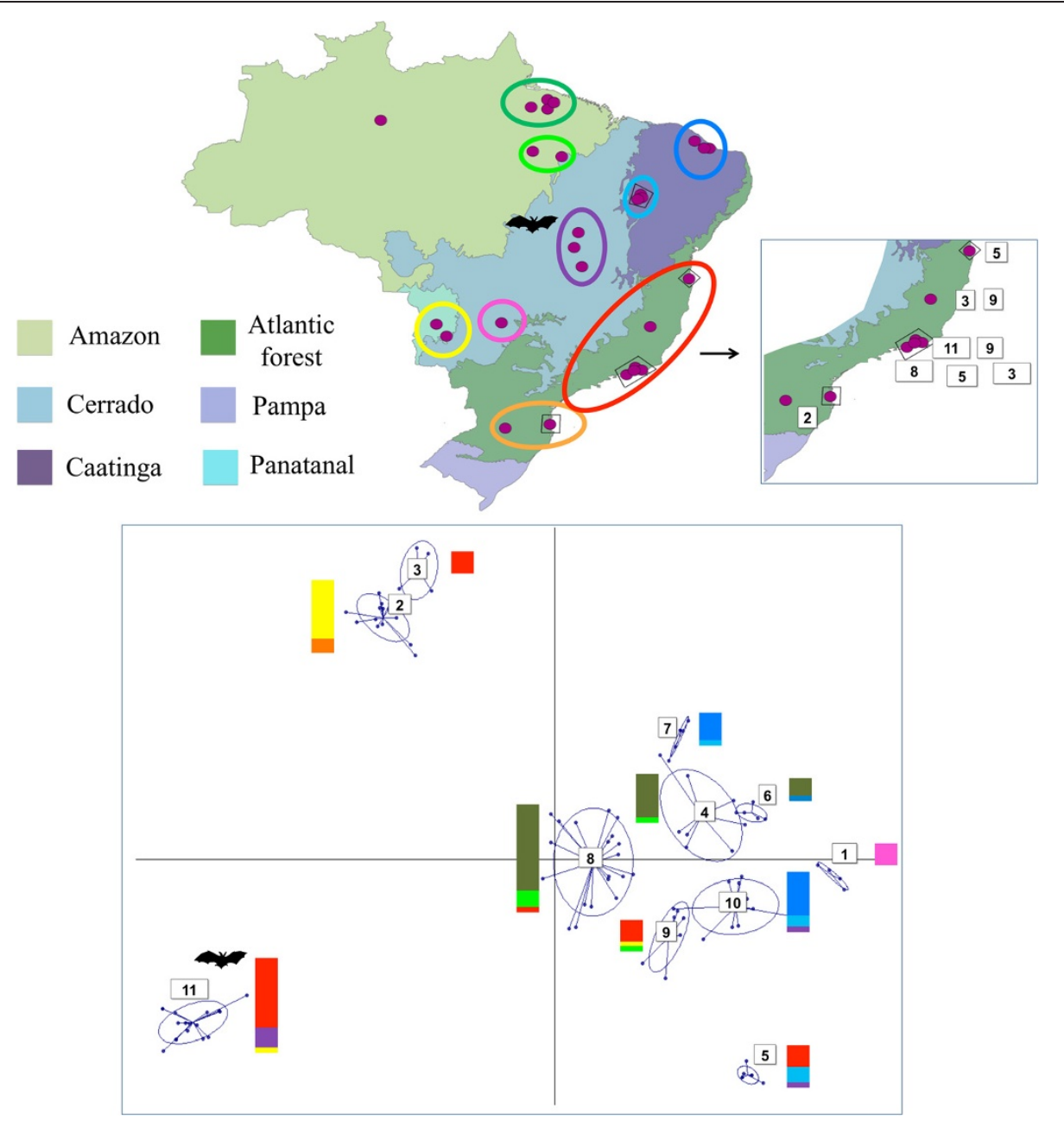

Figure 1 Composite map and multidimensional scaling plot depicting sample clustering by biome and geography among 107 Trypanosoma cruzi I isolates.

Table 1 Population genetic parameters across nine Trypanosoma cruzi I populations sampled from five biomes in Brazil

\begin{tabular}{|c|c|c|c|c|c|c|}
\hline Population & $\mathrm{N}$ & $A_{r} \pm S E$ & $\mathrm{D}_{\mathrm{AS}} \pm \mathrm{SD}$ & $\% \mathrm{PL} \mathrm{H}$ & $\% \mathrm{PL} \mathrm{Hd}^{\mathrm{b}}$ & $\mathrm{F}_{\mathrm{IS}} \pm \mathrm{SE}^{\mathrm{c}}$ \\
\hline Ceara & 14 & $1.746 \pm 0.121$ & $0.290 \pm 0.131$ & 0 & 0 & $0.020 \pm 0.012$ \\
\hline Goais & 4 & $1.734 \pm 0.101$ & $0.136 \pm 0.067$ & 0 & 0 & $-0.526 \pm 0.032$ \\
\hline PARA $A_{\text {NORTH }}$ & 28 & $2.134 \pm 0.143$ & $0.445 \pm 0.082$ & 0 & 19.2 & $0.147 \pm 0.008$ \\
\hline PARA $A_{\text {SOUTH }}$ & 5 & $2.027 \pm 0.152$ & $0.416 \pm 0.053$ & 0 & 0 & $0.250 \pm 0.019$ \\
\hline Pantanal & 13 & $1.698 \pm 0.121$ & $0.219 \pm 0.197$ & 26.3 & 5.2 & $0.068 \pm 0.029$ \\
\hline Piaui & 6 & $1.930 \pm 0.140$ & $0.357 \pm 0.188$ & 0 & 0 & $0.080 \pm 0.023$ \\
\hline Atlantic Forest & 27 & $2.010 \pm 0.133$ & $0.369 \pm 0.199$ & 33.3 & 33.3 & $0.077 \pm 0.015$ \\
\hline Santa Catarina & 3 & $1.412 \pm 0.098$ & $0.057 \pm 0.020$ & 0 & 0 & $-0.740 \pm 0.033$ \\
\hline Tocantins & 7 & $1.959 \pm 0.133$ & $0.362 \pm 0.221$ & 14.2 & 0 & $0.180 \pm 0.025$ \\
\hline
\end{tabular}

$N$ number of isolates in population.

$A_{r}$ allelic richness as a mean over loci \pm standard error, calculated in FSTAT.

$D_{A S}$ mean pair-wise inverse allele sharing between samples \pm standard deviation calculated in MICROSAT.

aProportion of loci showing significant excess heterozygosity after a sequential Bonferroni correction. Calculated in ARLEQUIN v3.1.

${ }^{b}$ Proportion of loci showing a significant deficit in heterozygosity after a sequential Bonferroni correction. Calculated in ARLEQUIN v3.1.

${ }^{\mathrm{c}}$ Mean FIS over loci \pm standard error, calculated in FSTAT. 
significance levels for $\mathrm{p}$ values derived after sequential Bonferroni correction to minimise the likelihood of Type 1 errors [32].

For the 19 locus dataset, individual level sample clustering was defined via a neighbour-joining tree based on pairwise distances between multilocus genotypes MLGs [evaluated using $D_{\mathrm{AS}}$ ( 1 - proportion of shared alleles at all loci/n)] calculated in MICROSAT [33] (Figure 2). For the 27 locus dataset we defined genetic composition via a $K$-means clustering algorithm, implemented in adegenet [34], with which the optimal number of populations is defined by reference to the Bayesian Information
Criterion. These groupings were subsequently submitted to a discriminant analysis of principal components (DAPC) [35], and the resulting plot is found in Figure 1.

\section{Maxicircle analysis}

Ten maxicircle sequence fragments were amplified and sequenced from fourteen T. cruzi clones (see Additional file 1: Table S1 for clone identity) following previously described protocols [28]. Sequence fragments were then concatenated in each sample and aligned against previously published sequences prior to analysis [28]. Phylogenies were inferred using Maximum-Likelihood (ML)

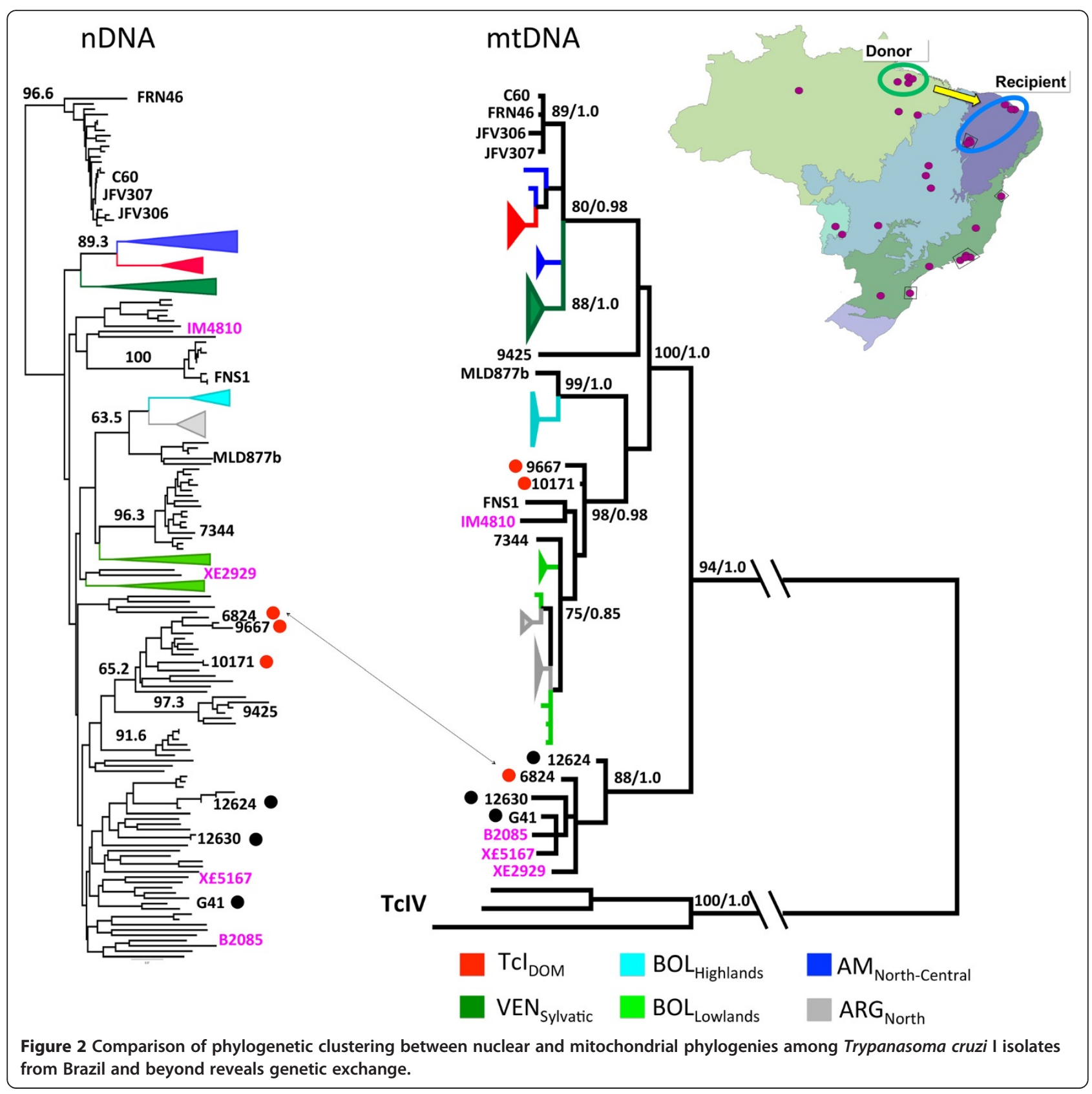


implemented in PhyML (4 substitution rate categories) [36]. The best-fit model of nucleotide substitution was selected from 88 models and its significance evaluated according to the Akaike Information Criterion (AIC) in jMODELTEST 1.0 [37]. The best model selected for this dataset was GTR $+\mathrm{I}+\mathrm{G}$. Bootstrap support for clade topologies was estimated following the generation of 1000 pseudo-replicate datasets. Bayesian phylogenetic analysis was performed using Mr BAYES v3.1 [38] (settings according to jMODELTEST 1.0). Five independent analyses were run using a random starting tree with three heated chains and one cold chain over 10 million generations with sampling every 10 simulations (25\% burn-in).

\section{Results}

Nuclear microsatellite loci demonstrated considerable genetic diversity among the 107 strains studied. For comparative purposes isolates were grouped a priori according to both geography and biome of origin (Figure 1). As such nine populations were defined. Sample assignment to these populations is presented in Additional file 1: Table S1 and population genetic parameters associated with them in Table 1. Of primary interest are sample size corrected values for allelic richness $\left(\mathrm{A}_{\mathrm{r}}\right) . \mathrm{A}_{\mathrm{r}}$ is highest among $P A R A_{\mathrm{NORTH}}$ and $P A R A_{\mathrm{SOUTH}}$ samples in the Eastern Amazon $\left(\mathrm{A}_{\mathrm{r}}=2.027 \& 2.134\right)$, as well as in the Atlantic Forest $\left(A_{r}=2.010\right)$ and Tocantins, in the Cerrado $\left(A_{r}\right.$ 1.959). While $A_{r}$ is a useful measure of overall sample size corrected genetic diversity, structured diversity within a population may be overlooked. We thus also calculated mean pairwise allele sharing $\left(\mathrm{D}_{\mathrm{AS}}\right)$ between multilocus genotypes (MLGs) in each population - Table 1 . The standard deviations associated with mean $D_{A S}$ values are particularly informative. Diverse populations with elevated standard deviations (e.g. Atlantic Forest $-0.369 \pm 0.199$, Tocantins - $0.362 \pm 0.221)$ are likely to possess intrapopulation sub-clusters. By contrast genetic diversity is uniformly distributed among samples within populations with low standard deviations about the mean $\mathrm{D}_{\mathrm{AS}}\left(P A R A_{\mathrm{NORTH}}-0.445 \pm 0.082, P A R A_{\text {SOUTH }}-0.416 \pm\right.$ $0.053)$. Observed heterozygosity varied considerably across populations. However, where population sizes $(\mathrm{N}>10)$ are likely to facilitate meaningful interpretation, positive values for $F_{\text {IS }}$ prevailed, and by inference heterozygous deficit compared to Hardy-Weinberg expectations (Table 1).

Sample clustering based on pair-wise nuclear genetic distances provides insight into the idiosyncratic patterns of genetic diversity noted across populations. As such, considerable admixture is present between multiple populations. This phenomenon is best represented by the composite bars adjacent to the clusters in the multidimensional scaling plot displayed in Figure 1. Samples recovered from the Atlantic Forest and Tocantins cluster among multiple, divergent groups. Meanwhile TcI from
PARA $A_{\mathrm{NORTH}}, P A R A_{\mathrm{SOUTH}}$ and Ceara occur among the same or closely related clusters. Remaining clusters represent intermediates between these two extremes. In summary, genetic diversity among some populations looks considerably more fragmented than among others. Mean pair-wise values for $\mathrm{D}_{\mathrm{AS}}$ and their associated SD seem to reflect this (Table 1 ).

Given the intense degree of admixture and substructure in several populations we decided not to calculate population specific linkage disequilibrium indices. Substructure is known to inflate such measures and increase the likelihood of a type 1 error [39]. Instead we chose to evaluate congruence between nuclear and mitochondrial genome clustering as evidence for rare genetic exchange events. To make such a comparison we incorporated previously published nuclear and mtDNA data into our dataset [28]. Figure 2 shows the resulting trees and the single recombinant we were able to detect mong the 14 clones assayed - 6824, isolated from Didelphis albiventris in the Caatinga, possesses a mitochondrial genome of Amazonian origin. The hypothetical direction of the introgression event (recipient and donor) is detailed in the map inset.

The inclusion of nuclear reference microsatellite profiles from throughout the Americas in Figure 2 provides insight into the wider affinities of the Brazilian isolates. Most notably, isolates belonging to cluster 11 in Figure 1 form a homogenous group that cluster basally, well outside global TcI diversity. GPI sequences for this group nonetheless confirmed this group as TcI and no affinities with Tcbat were apparent based on the same target (data not shown).

\section{Discussion}

TcI diversity in Brazil is clearly considerable by comparison to that in the rest of South, Central and North America. Figure 2 shows a comparison of isolates evaluated in this study with those analysed previously [27]. Nuclear genetic data (left hand tree) indicate a clade (corresponding to population 11 in Figure 1) that lies outside the known diversity of $\mathrm{TcI}$ in the Americas. The presence of a bat trypanosome among this group led us to suspect that this cluster may be Tcbat, a novel DTU with affiliations to TcI originally isolated from chiroptera in Sao Paolo state, but now recognised as more widespread [40,41]. However, sequence comparison of this clade and Tcbat at the GPI gene rejected this hypothesis (data not shown). In contrast, all remaining TcI isolates from Brazil fall alongside their congeners, including isolates from Bolivia and Argentina, but distinct from isolates north of the Amazon basin (Venezuela, North and Central America).

The available data suggest that genetic exchange is a fairly common phenomenon among TcI isolates [25,42], 
which is also capable of genetic recombination in the laboratory [43]. A consistent feature of genetic exchange events is the uniparental inheritance of mtDNA. At a population level, as well as between DTUs, these events lead to clear instances of mitochondrial introgression [25]. Thus a pair of isolates maybe highly genetically similar on a nuclear level, but lack any affinity between mitochondrial genomes. We identified one such hybrid among those clones we assayed - 6824. In a recent review, it was proposed that 'different evolutionary pressures and molecular clocks' between non-coding nuclear microsatellite and coding mtDNA, rather than genetic exchange, might account for such signals of introgression [44]. However, such a theory requires a situation in which two (or more) near identical nuclear genotypes (e.g. 6824 and 9667) experience radically different evolutionary pressures on their mitochondrial genomes, which end up closely resembling the mitochondrial genotype of nearby or sympatric clones, in this case from the same host (Didelphis albiventris). Given that this pattern of introgression fits precisely with that observed in hybrids in the laboratory [43], and between DTUs in the field (TcI/TcIV) [45], recombination is the only reasonable explanation.

Of particular interest in our study was the distribution and structure of genetic diversity within and between ecoregions. Admixture was most common in the Atlantic forest region, and largely absent from the Amazon region in Pará state (Figure 1). As such, samples from the Atlantic Forest region have strong affinity with those from around Brazil and are thus distributed across multiple genetic clusters in Figure 1. The inset in Figure 1 provides fine details of parasite genetic diversity in the Atlantic Forest region. Isolates at the northern extreme of this region have predictable affinity with samples from the Caatinga (cluster 5). However, admixture into Atlantic forest from other populations is far less predictable, especially from Amazonia, and the Pantanal, which lie thousands of kilometres from the Atlantic forest. The impact of Atlantic forest fragmentation on species abundance and diversity is well documented (e.g. [46-48]). Most studies report loss of alpha diversity correlating inversely with forest fragment size, within as well as between species $[46,49]$. In contrast, allelic richness indices in our study suggested substantial T. cruzi genetic diversity within the Atlantic Forest (Table 1). However, invasive species introductions are common in the Atlantic Forest region (e.g. [50]), and it seems that several long range introductions from distant populations may also explain the high genetic diversity of TcI in the region. Thus, unlike TcI populations from Amazonia and Caatinga, which generally exhibit high genetic diversity but little admixture, high genetic diversity in the Atlantic Forest region is explained by these introductions and associated admixture. Long-range sylvatic dispersal of $T$. cruzi can be achieved by bats. Indeed, the presence of T. cruzi clade trypanosomes in Africa can be explained by rapid aerial dispersal [51]. Cluster 11 contains several isolates from bats, which could explain the geographic diversity of isolates in this clade (Atlantic Forest, Pantanal, Cerrado), as well as its genetic homogeneity. However, other geographically diverse isolate groupings containing Atlantic Forest isolates have no link to volant mammals.

There is a circumstantial link between Atlantic Forest loss (88\% of its former extent [52]), human population density, and TcI genetic admixture in the region. T. cruzi infection is commonly termed a 'zoonosis', which implies unidirectional dispersion from sylvatic transmission cycles to man. Until the successful triatomine eradication campaigns of the 1970s and 1980s, domestic T. cruzi infection was endemic throughout much (although not all) of the Atlantic Forest region [21]. It is thus possible that many of these long-range introductions into the Atlantic are 'enzooses', i.e. TcI strains imported via immigrant human populations, which subsequently escaped in the local sylvatic environment.

\section{Conclusions}

Rather like primary rainforest, 'pristine' sylvatic T. cruzi diversity may be now relatively rare in South America, especially where human population densities and infections rates have been historically high. The presence of disturbed and admixed sylvatic $T$. cruzi populations in populous areas has major implications for the effective source attribution and thus future prevention of oral outbreaks [5]. Many such outbreaks have occurred in Brazil in recent years [53]. As such, the discrimination of the source of oral outbreak strains as being from either the local wild population or from another region via the importation of foodstuffs becomes complex. This is because the local wild strains themselves may represent long-range introductions. Nonetheless, admixture among sylvatic parasite populations has a possible role as a proxy for environmental disturbance. Future approaches could involve high-resolution genotyping and focused sampling of Atlantic forest fragments, including co-variates like mammalian and insect biodiversity, to further explore the use of T. cruzi as a sentinel species for ecosystem health.

\section{Additional file} Additional file 1: Table S1. Trypanosoma cruzi I isolates evaluated in
this study.

\section{Competing interests}

The authors declare they have no competing interests. The funders had no role in study design, data collection and analysis, decision to publish, or preparation of the manuscript. 


\section{Authors' contributions}

$V L$ and $M L$ generated the data. $V L, M L$ and $L M$ analysed the data. $V L, M M$ and $M L$ wrote manuscript. $A J$ and $M L$ designed the study. All authors read and approved the final version of the manuscript.

\section{Acknowledgements}

Thanks to Fabiana Rocha Lopez for critical input on the manuscript. This work was funded by a European Union FP7 consortium project, ChagasEpiNet, grant number: 223034

\section{Author details}

${ }^{1}$ Fundação Oswaldo Cruz, Rio de Janeiro, Brazil. ${ }^{2}$ Faculty of Infectious and Tropical Diseases, London School of Hygiene and Tropical Medicine, London, UK. ${ }^{3}$ Molecular Ecology and Fisheries Genetics Laboratory, School of Biological Sciences, Bangor University, Gwynedd LL57 2UW, UK.

Received: 27 February 2014 Accepted: 20 May 2014

Published: 5 June 2014

\section{References}

1. Rassi A Jr, Rassi A, Marin-Neto JA: Chagas disease. Lancet 2010, 375(9723):1388-1402

2. Yeo M, Acosta N, Llewellyn M, Sanchez H, Adamson S, Miles GA, Lopez E, Gonzalez N, Patterson JS, Gaunt MW, de Arias AR, Miles MA: Origins of Chagas disease: didelphis species are natural hosts of Trypanosoma cruzi I and armadillos hosts of Trypanosoma cruzi II, including hybrids. Int J Parasitol 2005, 35(2):225-233.

3. Hoare C: The Trypanosomes of Mammals. Oxford: Blackwell Scientific; 1972

4. Lent HWP: Revision of the Triatominae (Hemiptera, Reduviidae), and their significance as vectors of Chagas disease. Bull Am Mus Nat Hist 1979 163:125-520.

5. Segovia M, Carrasco HJ, Martinez CE, Messenger LA, Nessi A, Londono JC, Espinosa R, Martinez C, Alfredo M, Bonfante-Cabarcas R, Lewis MD, de Noya BA, Miles MA, Llewellyn MS: Molecular epidemiologic source tracking of orally transmitted Chagas disease, Venezuela. Emerg Infect Dis 2013, 19(7):1098-1101

6. Zingales B, Andrade SG, Briones MR, Campbell DA, Chiari E, Fernandes O, Guhl F, Lages-Silva E, Macedo AM, Machado CR, Machado CR, Miles MA, Romanha AJ, Sturm NR, Tibayrenc M, Schijman AG, Second Satellite Meeting: A new consensus for Trypanosoma cruzi intraspecific nomenclature: second revision meeting recommends Tcl to TcVl. Mem Inst Oswaldo Cruz 2009, 104(7):1051-1054

7. Lewis MD, Llewellyn MS, Yeo M, Acosta N, Gaunt MW, Miles MA: Recent, independent and anthropogenic origins of Trypanosoma cruzi hybrids. PLoS Negl Trop Dis 2011, 5(10):e1363.

8. Machado CA, Ayala FJ: Nucleotide sequences provide evidence of genetic exchange among distantly related lineages of Trypanosoma cruzi. Proc Natl Acad Sci U S A 2001, 98(13):7396-7401.

9. Flores-Lopez CA, Machado CA: Analyses of 32 loci clarify phylogenetic relationships among Trypanosoma cruzi lineages and support a single hybridization prior to human contact. PLoS Negl Trop Dis 2011, 5(8):e1272.

10. Marcili A, Valente VC, Valente SA, Junqueira AC, da Silva FM, Pinto AY, Naiff RD, Campaner M, Coura JR, Camargo EP, Miles MA, Teixeira MM: Trypanosoma cruzi in Brazilian Amazonia: lineages $\mathrm{TCl}$ and TClla in wild primates, Rhodnius spp. and in humans with Chagas disease associated with oral transmission. Int J Parasitol 2009, 39(5):615-623.

11. Cortez MR, Pinho AP, Cuervo P, Alfaro F, Solano M, Xavier SC, D'Andrea PS, Fernandes O, Torrico F, Noireau F, Jansen AM: Trypanosoma cruzi (Kinetoplastida Trypanosomatidae): ecology of the transmission cycle in the wild environment of the Andean valley of Cochabamba, Bolivia. Exp Parasitol 2006, 114(4):305-313.

12. Glasser N, Jansson K, Harrison S, Kleman J: The glacial geomorphology and Pleistocene history of South America between $38^{\circ} \mathrm{S}$ and $56^{\circ} \mathrm{S}$. Quat SC Rev 2008, 27:365-390.

13. Knapp S, Mallet J: Ecology. Refuting refugia? Science 2003, 300(5616):71-72.

14. Costa LP: The historical bridge between the Amazon and the Atlantic Forest of Brazil: a study of molecular phylogeography with small mammals. J Biogeogr 2003, 30:1365-2699.

15. Olson D, Dinerstein E, Wikramanayake E, Burgess N, Powell G, Underwood EC, d'Amico JA, Itoua I, Strand HE, Morrison JC, Loucks CJ, Allnutt TF, Ricketts TH, Kura Y, Lamoreux JF, Wettengel WW, Hedao P, Kassem KR:
Terrestrial ecoregions of the world: a new map of life on Earth. Bioscience 2001, 51:993-938.

16. Herrera L, D'Andrea PS, Xavier SC, Mangia RH, Fernandes O, Jansen AM: Trypanosoma cruzi infection in wild mammals of the National Park 'Serra da Capivara' and its surroundings (Piaui, Brazil), an area endemic for Chagas disease. Trans Roy Soc Trop Med Hyg 2005, 99(5):379-388.

17. Lisboa CV, Mangia RH, De Lima NR, Martins A, Dietz J, Baker AJ, Ramon-Miranda CR, Ferreira LF, Fernandes O, Jansen AM: Distinct patterns of Trypanosoma cruzi infection in Leontopithecus rosalia in distinct Atlantic coastal rainforest fragments in Rio de Janeiro-Brazil. Parasitology 2004, 129(Pt 6):703-711.

18. Herrera HM, Lisboa CV, Pinho AP, Olifiers N, Bianchi RC, Rocha FL, Mourao GM, Jansen AM: The coati (Nasua nasua, Carnivora, Procyonidae) as a reservoir host for the main lineages of Trypanosoma cruzi in the Pantanal region, Brazil. Trans Roy Soc Trop Med Hyg 2008, 102(11):1133-1139.

19. Rocha FL, Roque AL, de Lima JS, Cheida CC, Lemos FG, de Azevedo FC, Arrais RC, Bilac D, Herrera HM, Mourão G, Jansen AM: Trypanosoma cruzi infection in neotropical wild carnivores (Mammalia: Carnivora): at the top of the T. cruzi transmission chain. PLoS One 2013, 8(7):e67463.

20. Herrera HM, Abreu UG, Keuroghlian A, Freitas TP, Jansen AM: The role played by sympatric collared peccary (Tayassu tajacu), white-lipped peccary (Tayassu pecari), and feral pig (Sus scrofa) as maintenance hosts for Trypanosoma evansi and Trypanosoma cruzi in a sylvatic area of Brazil. Parasitol Res 2008, 103(3):619-624.

21. Schofield CJ, Dias JC: The Southern cone initiative against Chagas disease. Adv Parasitol 1999, 42:1-27.

22. Marcogliese DJ: Parasites of the superorganism: are they indicators of ecosystem health? Int J Parasitol 2005, 35(7):705-716

23. Wirth T, Meyer A, Achtman M: Deciphering host migrations and origins by means of their microbes. Mol Ecol 2005, 14(11):3289-3306.

24. Vaz VC, D'Andrea PS, Jansen AM: Effects of habitat fragmentation on wild mammal infection by Trypanosoma cruzi. Parasitology 2007, 134(Pt 12):1785-1793.

25. Ramirez JD, Guhl F, Messenger LA, Lewis MD, Montilla M, Cucunuba Z, Miles MA, Llewellyn MS: Contemporary cryptic sexuality in Trypanosoma cruzi. Mol Ecol 2012, 21(17):4216-4226.

26. Ceballos LA, Cardinal MV, Vazquez-Prokopec GM, Lauricella MA, Orozco MM Cortinas R, Schijman AG, Levin MJ, Kitron U, Gurtler RE: Long-term reduction of Trypanosoma cruzi infection in sylvatic mammals following deforestation and sustained vector surveillance in northwestern Argentina. Acta Trop 2006, 98(3):286-296.

27. Llewellyn MS, Miles MA, Carrasco HJ, Lewis MD, Yeo M, Vargas J, Torrico F, Diosque P, Valente V, Valente SA, Gaunt MW: Genome-scale multilocus microsatellite typing of Trypanosoma cruzi discrete typing unit I reveals phylogeographic structure and specific genotypes linked to human infection. PLoS Pathog 2009, 5(5):e1000410.

28. Messenger L, Llewellyn M, Bhattacharyya T, Franzén O, Lewis M, Ramírez J, Carrasco $\mathrm{H}$, Andersson B, Miles M: Multiple mitochondrial introgression events and heteroplasmy in Trypanosoma cruzi revealed by maxicircle MLST and Next Generation Sequencing. PLOS Negl Trop Dis 2011, In press.

29. Lauthier JJ, Tomasini N, Barnabe C, Rumi MM, D'Amato AM, Ragone PG, Yeo M, Lewis MD, Llewellyn MS, Basombrío MA, Miles MA, Tibayrenc M, Diosque P: Candidate targets for Multilocus Sequence Typing of Trypanosoma cruzi: validation using parasite stocks from the Chaco Region and a set of reference strains. Infect Genet Evol 2012, 12(2):350-358.

30. Yeo M, Lewis MD, Carrasco HJ, Acosta N, Llewellyn M, da Silva Valente SA, de Costa Valente $V$, de Arias AR, Miles MA: Resolution of multiclonal infections of Trypanosoma cruzi from naturally infected triatomine bugs and from experimentally infected mice by direct plating on a sensitive solid medium. Int J Parasitol 2007, 37(1):111-120

31. Goudet J: FSTAT Version 1.2: a computer program to calculate F-statistics. $J$ Heredity 1995, 86:485-486.

32. Rice W: Analyzing tables with statistical tests. Evolution 1989, 43:223-225.

33. Minch E, Ruíz-Linares A, Goldstein D, Feldman M, Cavalli-Sforza L: MICROSATthe Microsatellite Distance Program. Stanford: Stanford University Press; 1995.

34. Jombart $\mathrm{T}$ : adegenet: a R package for the multivariate analysis of genetic markers. Bioinformatics 2008, 24(11):1403-1405.

35. Jombart T, Devillard S, Balloux F: Discriminant analysis of principal components: a new method for the analysis of genetically structured populations. BMC Genet 2010, 11:94.

36. Guindon S, Dufayard JF, Lefort V, Anisimova M, Hordijk W, Gascuel O: New algorithms and methods to estimate maximum-likelihood 
phylogenies: assessing the performance of PhyML 3.0. Syst Biol 2010, 59(3):307-321.

37. Posada D, Crandall KA: MODELTEST: testing the model of DNA substitution. Bioinformatics 1998, 14(9):817-818.

38. Ronquist F, Huelsenbeck JP: MrBayes 3: Bayesian phylogenetic inference under mixed models. Bioinformatics 2003, 19(12):1572-1574.

39. Maynard Smith J, Smith NH, O'Rourke M, Spratt BG: How clonal are bacteria? Proc Natl Acad Sci India 1993, 90(10):4384-4388.

40. Marcili A, Lima L, Cavazzana M, Junqueira AC, Veludo HH, Maia Da Silva F, Campaner M, Paiva F, Nunes VL, Teixeira MM: A new genotype of Trypanosoma cruzi associated with bats evidenced by phylogenetic analyses using SSU rDNA, cytochrome $b$ and Histone $\mathrm{H} 2 \mathrm{~B}$ genes and genotyping based on ITS1 rDNA. Parasitology 2009, 136(6):641-655.

41. Ramirez JD, Tapia-Calle G, Munoz-Cruz G, Poveda C, Rendon LM, Hincapie E, Guhl F: Trypanosome species in neo-tropical bats: biological, evolutionary and epidemiological implications. Infect Genet Evol 2013.

42. Ocana-Mayorga S, Llewellyn MS, Costales JA, Miles MA, Grijalva MJ: Sex, subdivision, and domestic dispersal of Trypanosoma cruzi lineage I in southern Ecuador. PLoS Negl Trop Dis 2011, 4(12):e915.

43. Gaunt MW, Yeo M, Frame IA, Stothard JR, Carrasco HJ, Taylor MC, Mena SS, Veazey P, Miles GA, Acosta N, Carrasco HJ, Taylor MC, Mena SS, Veazey P, Miles GA, Acosta N, de Arias AR, Miles MA: Mechanism of genetic exchange in American trypanosomes. Nature 2003, 421(6926):936-939.

44. Tibayrenc M, Ayala FJ: How clonal are Trypanosoma and Leishmania? Trends Parasitol 2013, 29(6):264-269.

45. Roellig DM, Savage MY, Fujita AW, Barnabe C, Tibayrenc M, Steurer FJ, Yabsley MJ: Genetic variation and exchange in Trypanosoma cruzi isolates from the United States. PLoS One 2013, 8(2):e56198.

46. Gonçalves-Souza T, Matallana G, Brescovit AD: Effects of habitat fragmentation on the spider community (Arachnida, Araneae) in three Atlantic forest remnants in Southeastern Brazil. Revista ibérica de aracnología 2008, 16:35-42.

47. Ogrzewalska M, Uezu A, Jenkins CN, Labruna MB: Effect of forest fragmentation on tick infestations of birds and tick infection rates by rickettsia in the Atlantic forest of Brazil. EcoHealth 2011, 8(3):320-331.

48. Santos BA, Arroyo-Rodriguez V, Moreno CE, Tabarelli M: Edge-related loss of tree phylogenetic diversity in the severely fragmented Brazilian Atlantic forest. PLoS One 2010, 5(9):e12625.

49. Haag T, Santos AS, Sana DA, Morato RG, Cullen L Jr, Crawshaw PG Jr, De Angelo C, Di Bitetti MS, Salzano FM, Eizirik E: The effect of habitat fragmentation on the genetic structure of a top predator: loss of diversity and high differentiation among remnant populations of Atlantic Forest jaguars (Panthera onca). Mol Ecol 2010, 19(22):4906-4921.

50. Oliveira L, Viveiros-Grelle C: Introduced primate species of an Atlantic Forest region in Brazil: present and future implications for the native fauna. Trop Conserv Sci 2012, 1:113-243.

51. Hamilton PB, Teixeira MM, Stevens JR: The evolution of Trypanosoma cruzi: the 'bat seeding' hypothesis. Trends Parasitol 2012, 28(4):136-141.

52. Galindo-Leal CGC, Ibsen (Eds): The Atlantic Forest of South America: Biodiversity Status, Threats, and Outlook. Washington DC: Island Press; 2003.

53. Shikanai-Yasuda MA, Carvalho NB: Oral transmission of Chagas disease. Clin Infect Dis 2012, 54(6):845-852.

\section{doi:10.1186/1756-3305-7-263}

Cite this article as: Lima et al:: Wild Trypanosoma cruzi I genetic diversity in Brazil suggests admixture and disturbance in parasite populations from the Atlantic Forest region. Parasites \& Vectors 2014 7:263.

\section{Submit your next manuscript to BioMed Central and take full advantage of:}

- Convenient online submission

- Thorough peer review

- No space constraints or color figure charges

- Immediate publication on acceptance

- Inclusion in PubMed, CAS, Scopus and Google Scholar

- Research which is freely available for redistribution 